\title{
Sosialisasi E-learning Sinau Bareng secara Virtual bagi Guru SMKN 13 Surabaya
}

\author{
Lestari Retnawati \\ Universitas Wijaya Kusuma Surabaya
}

\author{
Nia Saurina \\ Universitas Wijaya Kusuma Surabaya
}

\author{
Udik Pudjianto \\ BPPAUD \& DIKMAS Jawa Timur
}

\begin{abstract}
The development of technology has a big influence in the world, even on every aspect of human life, one of which is the field of education. There is a need to change the teaching methods so that learning becomes more interactive. In the current situation, the world is being tested with a health problem, namely, the Corona (COVID-19) pandemic which is very influential in every aspect of life. Online learning is no longer new learning in schools. Through electronic media or better known as e-learning, the teaching and learning process can be done without doing face-to-face between teachers and students and is no longer limited by time and place. E-learning is one solution to the problems of the education world which is increasingly busy with various services that offer flexibility and high mobility. Universitas Wijaya Kusuma Surabaya (UWKS) collaborates with SMKN 13 Surabaya in improving teacher competency by providing Sinau Bareng e-learning socialization for teachers of SMKN 13 Surabaya and later will be used by SMKN 13 Surabaya teachers during the COVID-19 pandemic in the learning process. This article will explain the community service activities, especially in SMKN 13 Surabaya to guide teachers regarding the use of e-learning as a media that can foster student interest in learning so that the learning process will be more interesting and the material delivered by the teacher will be accepted by students easier.
\end{abstract}

Keywords: COVID-19; E-Learning; Teacher; Learning media; Technology

\begin{abstract}
Abstrak
Perkembangan teknologi memberikan pengaruh besar di dunia, bahkan hingga ke setiap aspek kehidupan manusia, salah satu di antaranya adalah bidang pendidikan. Perubahan metode pengajaran perlu dilakukan agar pembelajaran dapat berlangsung dengan lebih interaktif. Saat ini, dunia sedang diuji dengan suatu permasalahan kesehatan, yaitu pandemik Corona (COVID-19). Hal ini sangat berpengaruh juga pada setiap aspek kehidupan. Pembelajaran daring bukan lagi menjadi pembelajaran yang baru di sekolah-sekolah. Melalui media elektronik atau yang lebih dikenal dengan e-learning, proses belajar-mengajar dapat dilakukan tanpa adanya tatap muka antara pengajar dan peserta didik serta tidak lagi dibatasi oleh waktu dan tempat. E-learning menjadi salah satu solusi bagi permasalahan dunia pendidikan yang semakin sibuk dengan berbagai layanan yang menawarkan fleksibilitas dan mobilitas yang tinggi. Universitas Wijaya Kusuma Surabaya (UWKS) bekerja sama dengan SMKN 13 Surabaya dalam melakukan peningkatan kompetensi guru melalui kegiatan Sosialisasi E-learning Sinau Bareng secara Virtual bagi Guru SMKN 13 Surabaya dan nantinya akan digunakan oleh guru SMKN 13 Surabaya selama masa pandemik COVID-19 dalam proses belajar-mengajar. Di dalam artikel ini, akan dipaparkan mengenai kegiatan pengabdian kepada masyarakat, khususnya di SMKN 13 Surabaya, dalam rangka memberikan pengarahan kepada guru mengenai penggunaan e-learning sebagai media yang dapat menumbuhkan minat belajar siswa sehingga proses pembelajaran akan terasa lebih menarik. Selain itu, materi yang disampaikan guru juga akan lebih mudah diterima oleh siswa.
\end{abstract}

Kata kunci: COVID-19; E-learning; Guru; Media belajar; Teknologi

\section{Pendahuluan}

Perkembangan teknologi informasi dan komunikasi (TIK) dalam bidang pendidikan saat ini sudah semakin maju. Seiring dengan perkembangan teknologi di era digital, berbagai usaha ditempuh untuk meningkatkan kualitas pendidikan dalam rangka meningkatkan perkembangan ilmu pengetahuan dan teknologi. 
Jangkauan pemanfaatan teknologi dalam dunia pendidikan sudah sangat meluas, mulai dari jenjang pendidikan dasar, menengah, hingga ke perguruan tinggi, meskipun variasi dan fokus pemanfaatannya berbeda pada masing-masing institusi. Dalam upaya untuk meningkatkan mutu pendidikan di Indonesia, pemerintah selalu berusaha memperbaiki kurikulum pendidikan, dengan harapan perubahan kurikulum mampu membentuk sumber daya manusia yang berkualitas dan berguna bagi pembangunan bangsa. Upaya-upaya tersebut dilandasi suatu kesadaran bahwa betapa pentingnya peranan pendidikan dalam pengembangan sumber daya manusia dan pengembangan watak bangsa (Mulyasa, 2005).

Dalam menyikapi perkembangan serta kemajuan tekologi tersebut serta kondisi dunia yang sedang diuji dengan suatu permasalahan kesehatan, yaitu pandemik Corona (COVID-19), para pendidik dituntut untuk dapat menguasai teknologi agar mampu mengembangkan materimateri pembelajaran berbasis teknologi dan memanfaatkan teknologi sebagai media pembelajaran. Gagne \& Briggs (1975) dalam Arsyad (2002) mengemukakan bahwa media pembelajaran meliputi alat yang secara fisik digunakan untuk menyampaikan isi materi pengajaran, yang terdiri dari buku, tape recorder, kaset, kamera video, video recorder, film, slide (gambar bingkai), foto gambar, grafik, televisi, dan komputer. Kekuatan TIK pada pembelajaran akan melahirkan konsep baru yang disebut dengan e-learning. E-learning merupakan segala aktivitas belajar yang menggunakan bantuan teknologi elektronik (Rusman, 2012). Melalui e-learning, proses belajar-mengajar dapat dilakukan tanpa adanya tatap muka antara pengajar dan peserta didik serta tidak lagi dibatasi oleh waktu dan tempat. E-learning menjadi salah satu solusi bagi permasalahan dunia pendidikan dan COVID-19. Salah satu contoh e-learning yang pernah diterapkan sebelumnya antara lain oleh Hatip dkk. (2019), yakni berupa bantuan pemanfaatan e-learning berbasis media sosial Edmodo bagi para guru di SD Negeri Mulyorejo I, Surabaya.

Sebagai bentuk pelaksaan salah satu tridarma perguruan tinggi, yaitu pengabdian kepada masyarakat, Dosen Fakultas Teknik, khususnya Program Studi Teknik Informatika, Universitas Wijaya Kusuma Surabaya berinisiatif memberikan sosialisasi e-learning Sinau Bareng secara virtual bagi guru SMKN 13 Surabaya, dengan harapan dapat menumbuhkan minat belajar siswa sekaligus memberikan imbauan kepada siswa untuk aktif dalam memanfaatkan e-learning sebagai media belajar.

Tujuan yang akan dicapai dari program ini ialah memberikan sosialisasi dan pengetahuan bagi guru sebagai penunjang kegiatan proses belajar khususnya untuk penggunaan e-learning yang dapat menunjang prestasi siswa di dalam proses pembelajaran. Manfaat yang dapat diperoleh yaitu untuk mengembangkan tradisi keilmuan pada lembaga-lembaga pendidikan seperti sekolah, madrasah, perguruan tinggi dan sejenisnya, serta mampu meningkatkan dan mengembangkan mutu dari proses belajar-mengajar.

\section{Metode Pelaksanaan}

Kegiatan pengabdian kepada masyarakat (penmas) dengan tema Sosialisasi E-learning Sinau Bareng secara Virtual bagi Guru SMKN 13 Surabaya bertujuan untuk membantu agar guru lebih kreatif dan mudah dalam memanfaatkan media elektronik sebagai media belajar melalui $e$ learning sehingga kegiatan belajar dapat dilakukan tidak hanya melalui tatap muka antara siswa dan guru di dalam kelas. Peserta sosialisasi ini merupakan perwakilan guru dari SMKN 13 Surabaya.

Persiapan yang baik dalam pelaksanaan kegiatan perlu dilakukan untuk menghindari permasalahan yang mungkin akan terjadi. Hal yang terkait dalam tahap persiapan antara lain: (1) Pengoordinasian kegiatan dengan mitra, dalam hal ini Kepala Sekolah SMKN 13 Surabaya. Pada tahap ini, dibahas tentang kegiatan pengabdiaan masyarakat yang akan dilakukan, materi yang akan disampaikan, serta penetapan jadwal kegiatan; (2) Pembicaraan mengenai waktu pelaksanaan kegiatan dengan mendatangi perwakilan guru di SMKN 13 Surabaya serta 
penunjukan salah satu guru sebagai operator di SMKN 13 Surabaya; (3) Persiapan perlengkapan berupa komputer standar dengan sistem operasi Windows; (4) Persiapan materi yang akan disampaikan berupa tutorial/langkah-langkah penggunaan e-learning; (5) Pelaksanaan kegiatan; dan (6) Pembuatan laporan kegiatan.

Kegiatan inti dilaksanakan selama dua hari pada Selasa-Rabu, 9-10 Juni 2020, pukul 10.00-12.00 WIB di SMKN 13 Surabaya. Detail kegiatan yang dilakukan selama pelatihan tercantum pada Tabel 1.

Tabel 1. Jadwal Pelaksanaan Kegiatan Pengabdian Masyarakat Hari Pertama

\begin{tabular}{ccll}
\hline No. & Waktu & Kegiatan & Keterangan \\
\hline 1 & $10.00-10.15$ & Pesrsiapan & Seluruh peserta VC: \\
& & Moderator: Ketua Penmas & - Dosen TIF UWKS \\
& & - Guru dan operator sekolah \\
\hline 2 & \multirow{2}{*}{$10.15-10.30$} & Pembukaan dan Perkenalan & Seluruh peserta VC: \\
& & Moderator: Ketua Penmas & - Dosen TIF UWKS. \\
& & - Guru dan operator sekolah \\
\hline 3 & \multirow{2}{*}{$10.30-12.00$} & Pelatihan & Seluruh peserta VC: \\
& & Pembicara Penmas Dosen UWKS & - Dosen TIF UWKS \\
& & & (pasif hanya mendengarkan) \\
& & & - Guru dan operator sekolah \\
& & & (aktif dan tanya jawab) \\
\hline
\end{tabular}

Tabel 1 menjelaskan proses kegiatan yang dilaksanakan pada hari pertama. Pada kegiatan hari pertama, pembelajaran difokuskan kepada guru dan operator sekolah SMKN 13 Surabaya.

Tabel 2. Jadwal Pelaksanaan Kegiatan Pengabdian Masyarakat Hari Kedua

\begin{tabular}{ccll}
\hline No. & Waktu & Kegiatan & Keterangan \\
\hline 1 & $10.00-10.15$ & Persiapan & Peserta VC: Operator sekolah \\
& & Moderator: Ketua Penmas & \\
\hline 2 & $10.15-12.00$ & Pelatihan & Peserta VC: Operator sekolah \\
& & Pembicara Penmas Dosen UWKS & \\
\hline
\end{tabular}

Tabel 2 menjelaskan proses kegiatan yang dilaksanakan pada hari kedua. Pada kegiatan hari kedua, pembelajaran difokuskan hanya kepada operator sekolah SMKN 13 Surabaya.

\section{Hasil dan Pembahasan}

Beberapa kegiatan yang dilakukan ialah sosialisasi dan tutorial penggunaan e-learning sebagai media belajar bagi guru SMKN 13 Surabaya. Pada kegiatan pengabdian kepada masyarakat ini disampaikan materi penggunaan media belajar e-learning berupa media online berbasis Moodle. Aktivitas proses sosialisasi e-learning Sinau Bareng bagi guru SMKN 13 Surabaya tersaji pada Gambar 1-9.

Gambar 1 menjelaskan kegiatan pengabdian masyarakat yang dilaksanakan melalui video konferensi berbasis BigBlueButton yang bertujuan untuk memperkenalkan diri, baik pembicara maupun peserta pelatihan. Kegiatan pada hari pertama ini diikuti oleh 11 orang sebagai pembicara dan 20 orang sebagai peserta pelatihan. Selain itu, kegiatan pada hari pertama ini bertujuan untuk menyampaikan tujuan kegiatan, yaitu mengadakan kegiatan pelatihan e-learning bagi guru SMKN 13 Surabaya. 


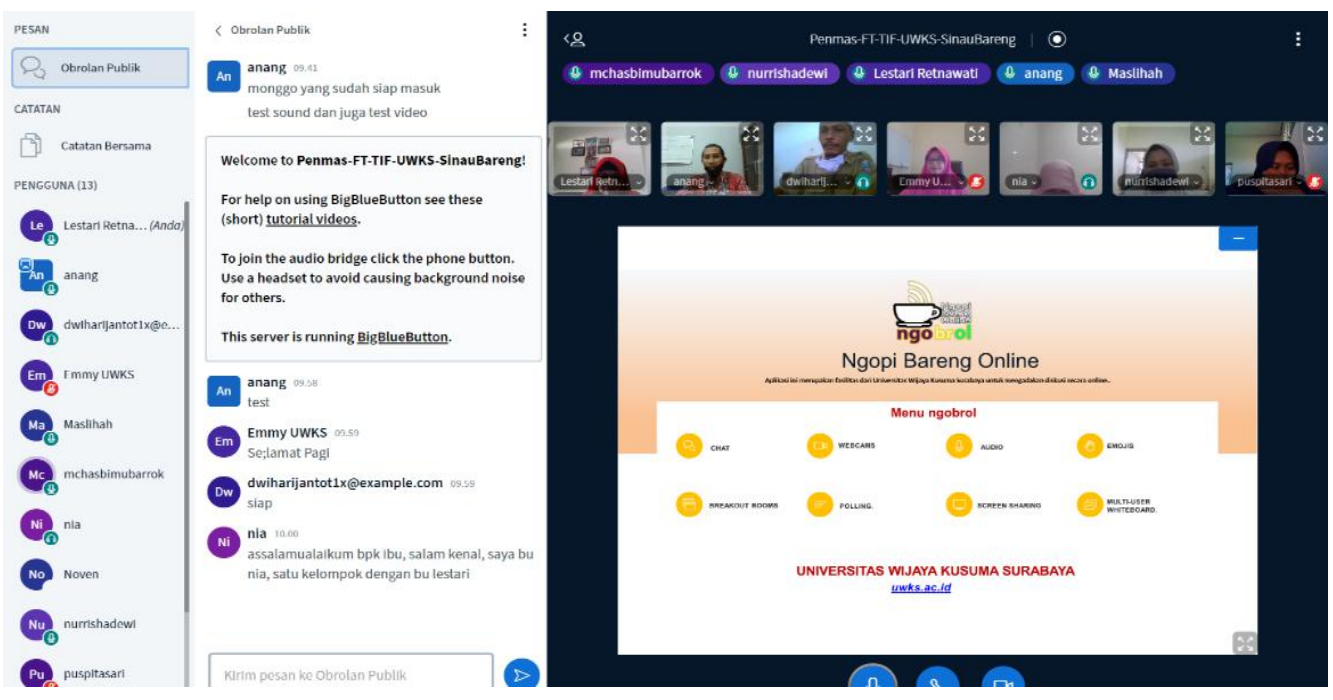

Gambar 1. Hari Pertama, Persiapan Sosialisasi Guru-Guru SMKN 13 Surabaya dan Dosen-Dosen Teknik Informatika, UWKS

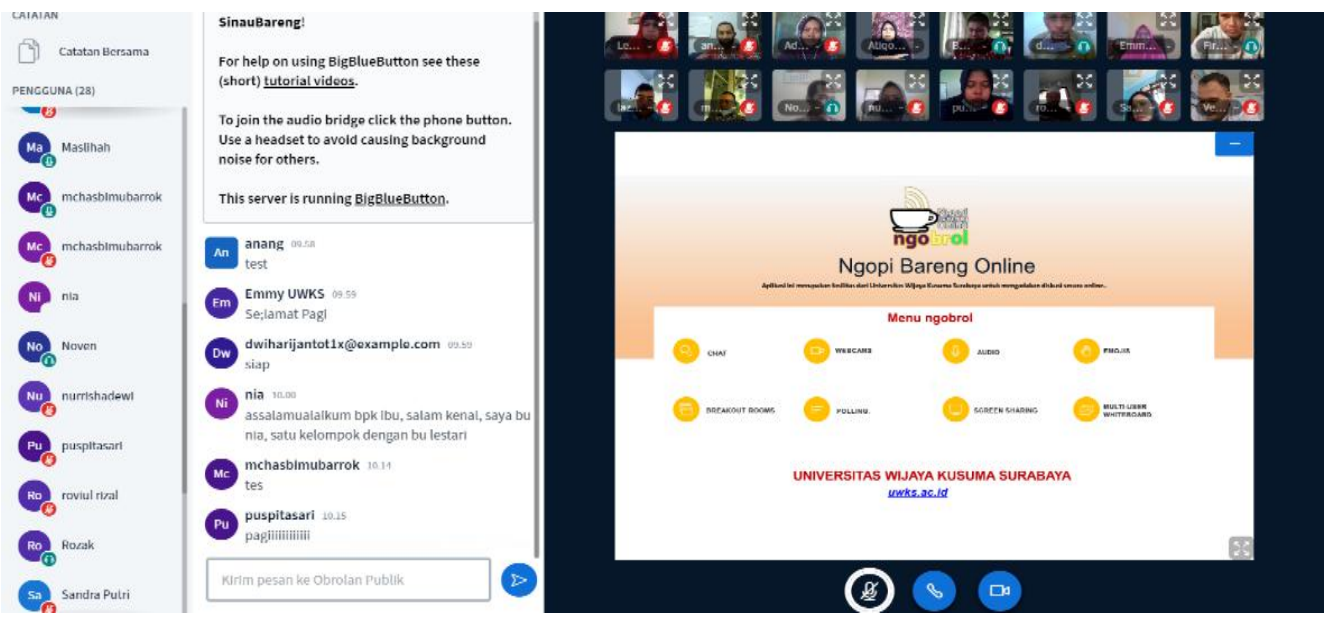

Gambar 2. Pelatihan Pembicara Penmas oleh Dosen UWKS

Gambar 2 menjelaskan kegiatan pengabdian masyarakat yang dilakukan pada hari kedua. Kegiatan ini bertujuan untuk mengenalkan fitur-fitur yang dimiliki e-learning Sinau Bareng kepada peserta pelatihan.

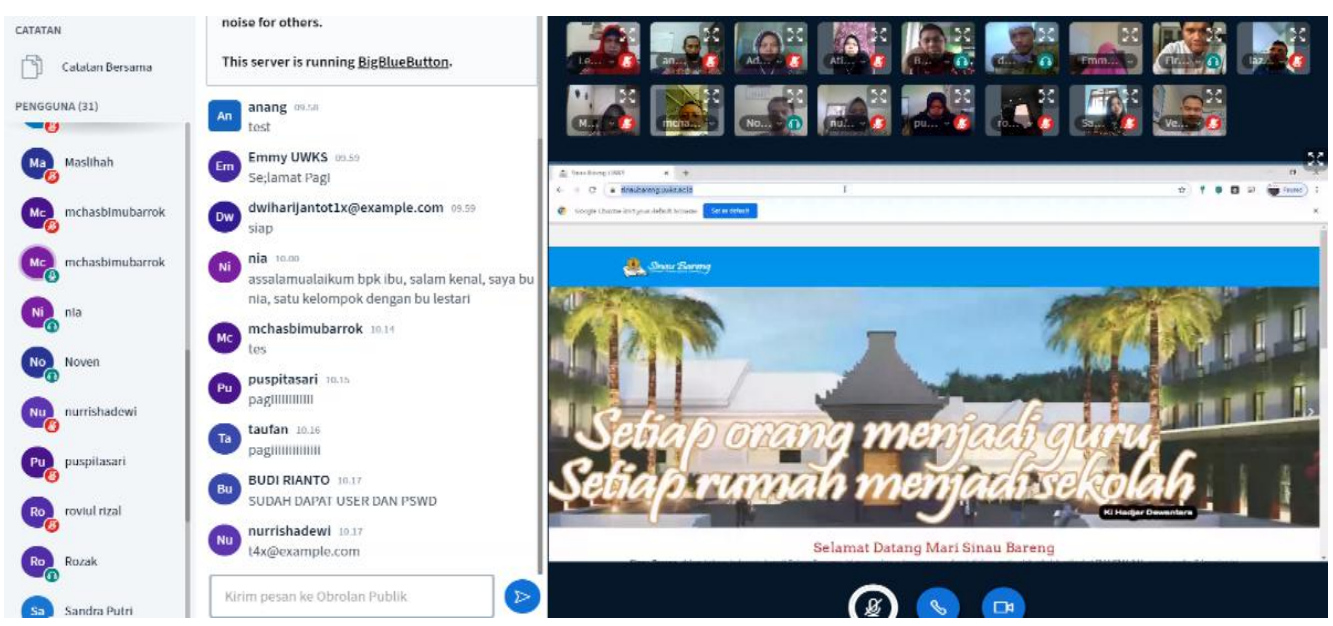

Gambar 3. Tampilan Depan (Pertama) 
Gambar 3 menjelaskan tampilan halaman pertama dari e-learning Sinau Bareng. Pada gambar terlihat logo Universitas Wijaya Kusuma Surabaya (UWKS) yang berupa candi Penataran.
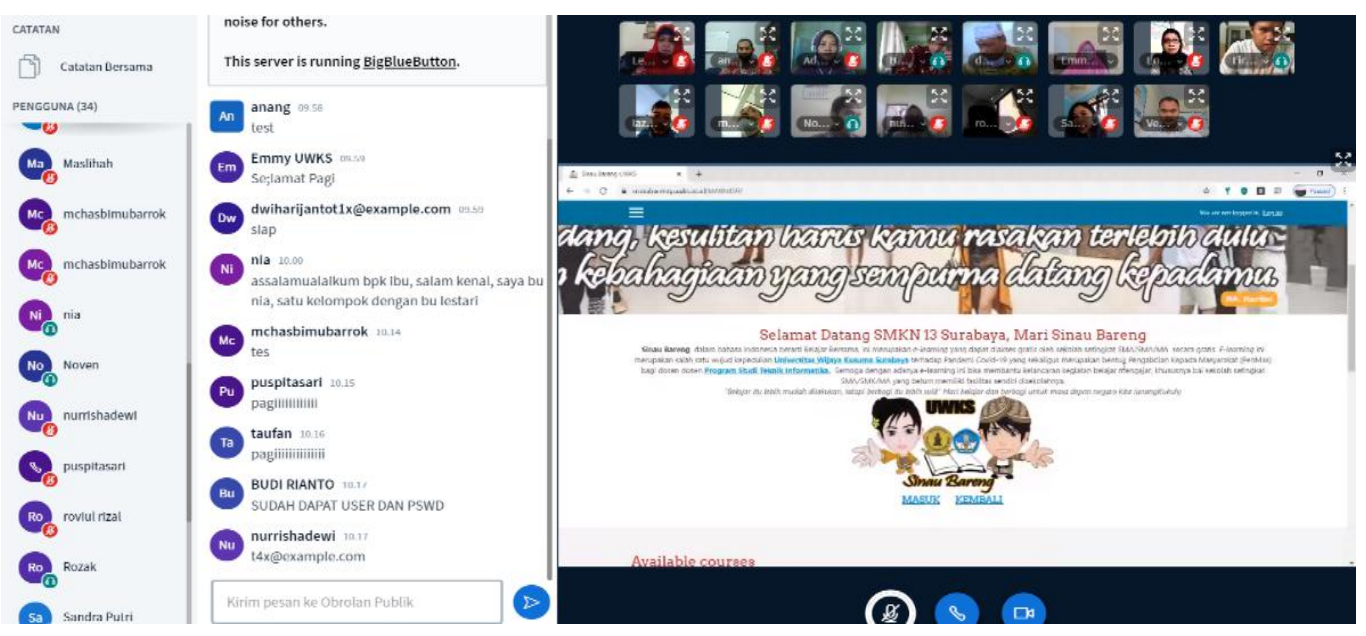

Gambar 4. Tampilan Depan Kedua

Gambar 4 menjelaskan tampilan halaman utama kedua. Pada sistem e-learning Sinau Bareng ini, terdapat informasi berupa kerja sama antara UWKS dengan SMKN 13 Surabaya.
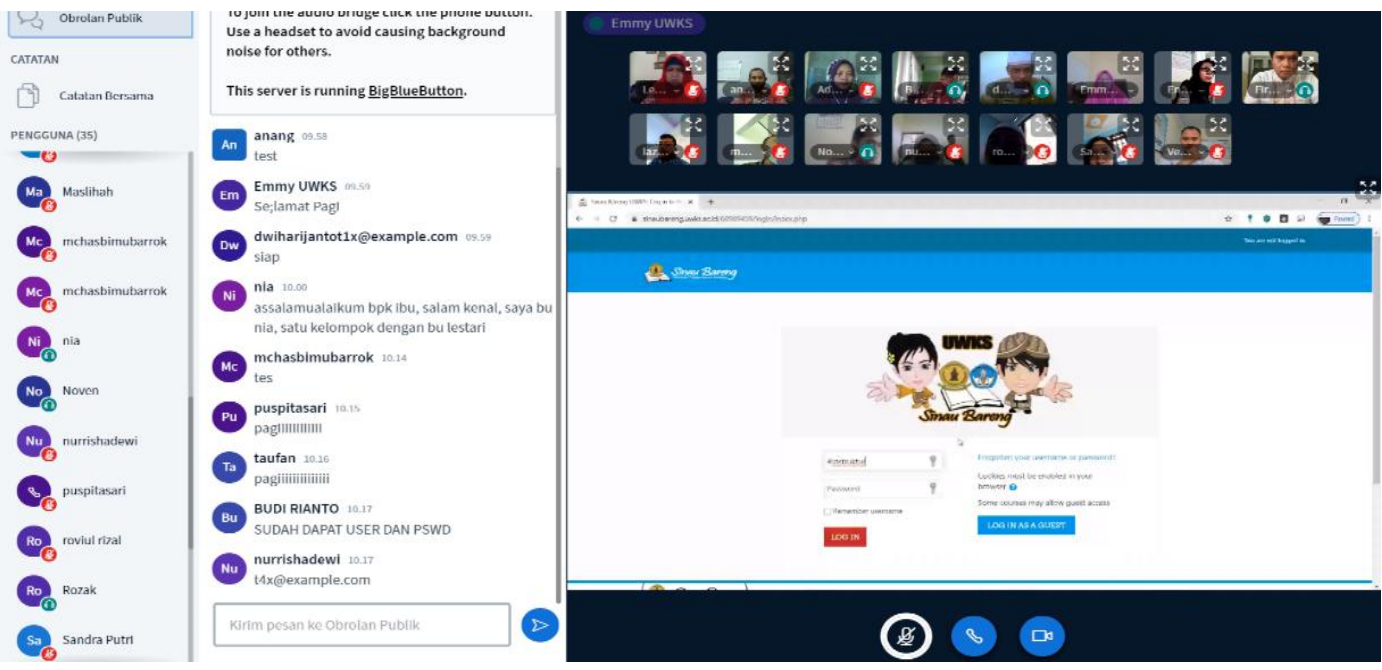

Gambar 5. Proses Pelatihan dengan Melakukan Login

Gambar 5 menjelaskan tampilan login yang dapat digunakan oleh guru SMKN 13 Surabaya untuk memulai menggunakan e-learning Sinau Bareng. Untuk pertama kalinya, UWKS memberikan informasi kepada guru SMKN 13 Surabaya berupa username dan password agar dapat login ke e-learning Sinau Bareng. Untuk pemakaian e-learning Sinau Bareng selanjutnya, para guru SMKN 13 Surabaya dapat mengubah sendiri username dan password sesuai kebutuhan.

Gambar 6 menjelaskan tampilan e-learning Sinau Bareng untuk mata pelajaran Bahasa Inggris setelah login. Para guru dapat memasukkan mata pelajaran ke e-learning sesuai kebutuhan. Selain itu para guru dapat memasukkan materi pelajaran sesuai jumlah pertemuan mata pelajaran.

Gambar 7 menjelaskan tampilan peserta sosialisasi guru-guru SMKN 13 Surabaya dan dosen-dosen Teknik Informatika UWKS. Tahun 2020 merupakan tahun tersulit untuk melakukan pembelajaran tatap muka karena adanya pandemik COVID-19 sehingga kegiatan pengabdian masyarakat ini merupakan pertama kalinya dilakukan tanpa tatap muka antara guru dan dosen. 


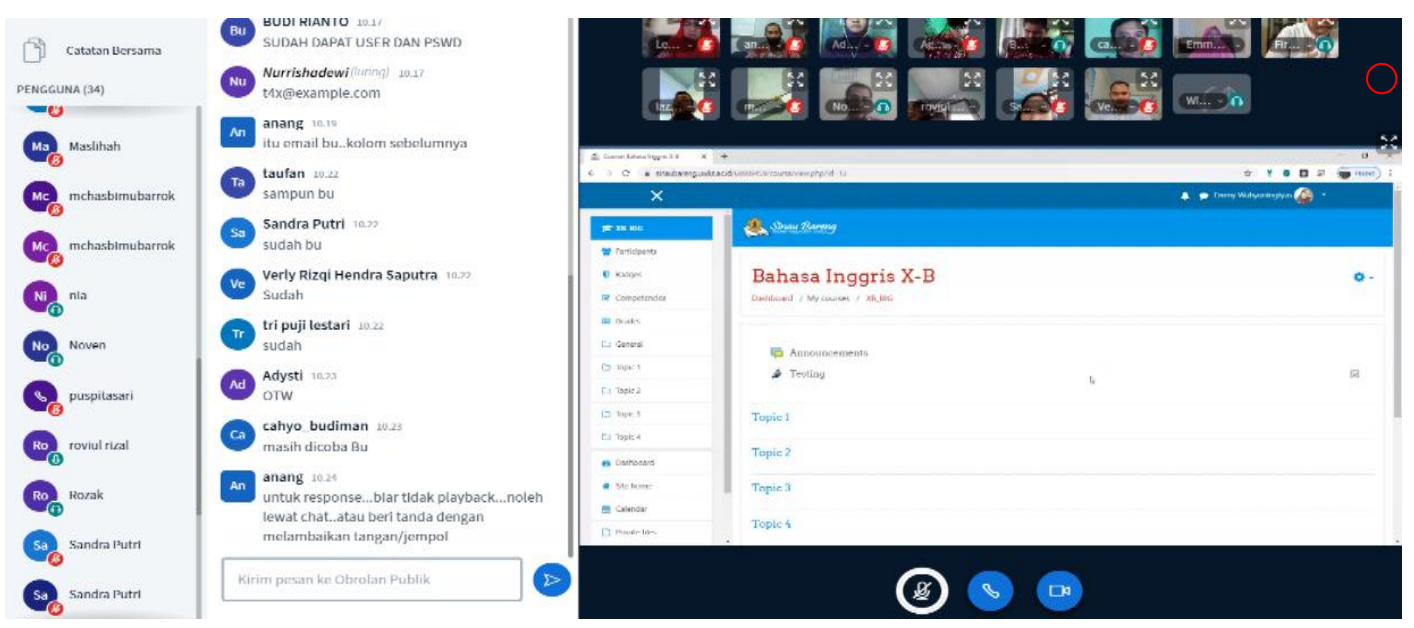

Gambar 6. Tampilan E-Learning

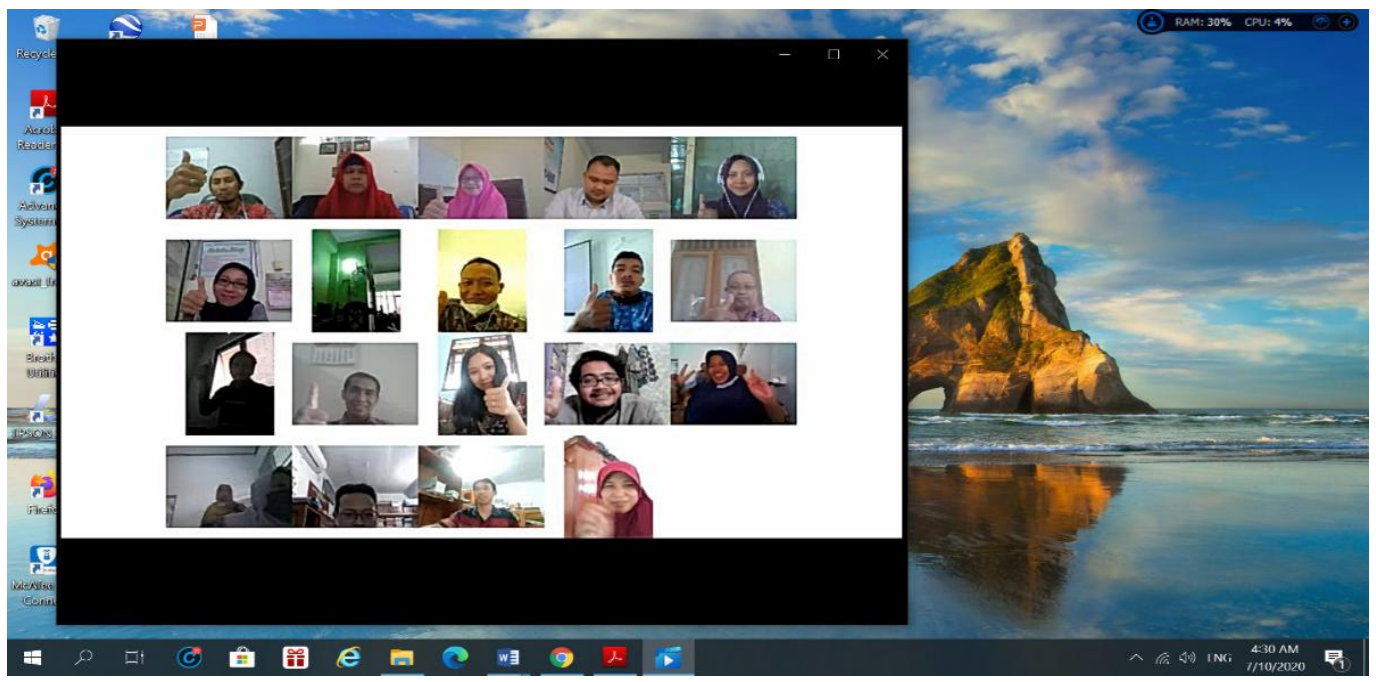

Gambar 7. Tampilan Peserta Sosialisasi, Guru-Guru SMKN 13 Surabaya dan Dosen-Dosen Teknik Informatika UWKS

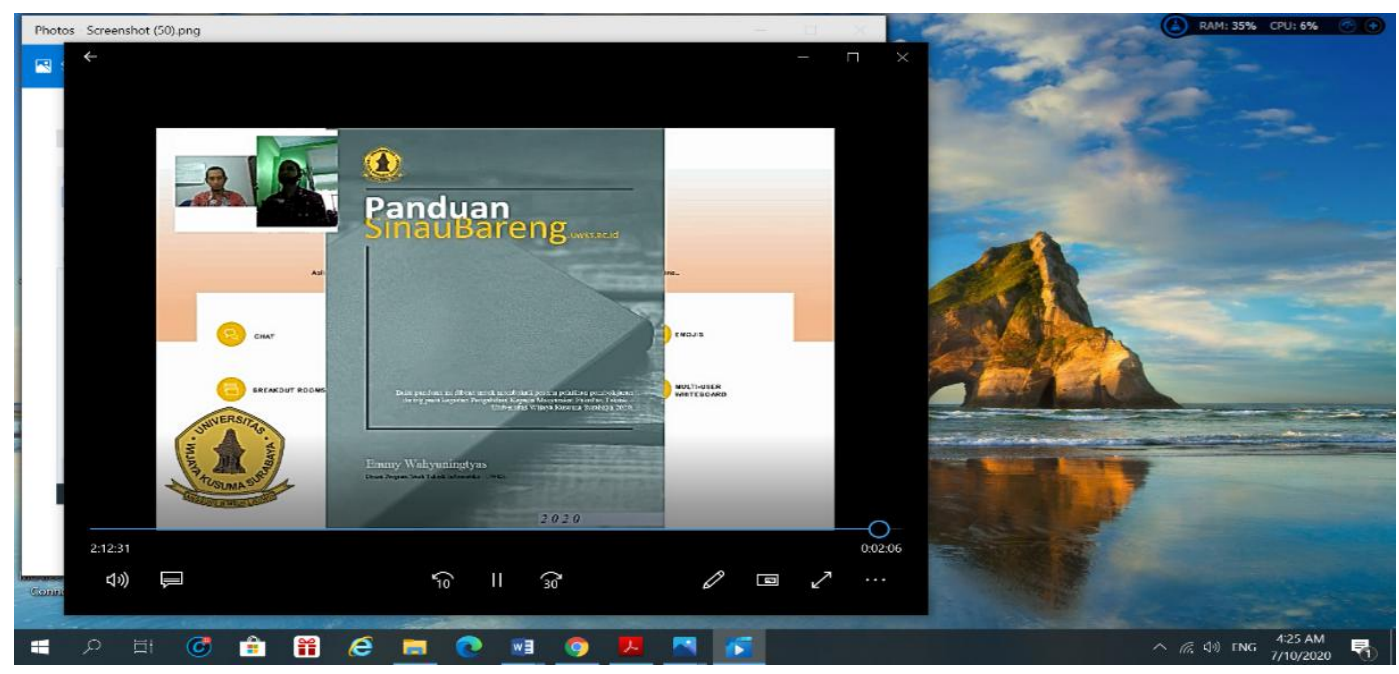

Gambar 8. Panduan/Tutorial E-Learning 
Gambar 8 menjelaskan tampilan panduan/tutorial e-learning yang bisa didapatkan oleh guru SMKN 13 Surabaya melalui e-learning Sinau Bareng. Pada panduan ini, dijelaskan secara lengkap bagaimana guru dapat menggunakan e-learning Sinau Bareng untuk kebutuhan kegiatan proses belajar-mengajar.

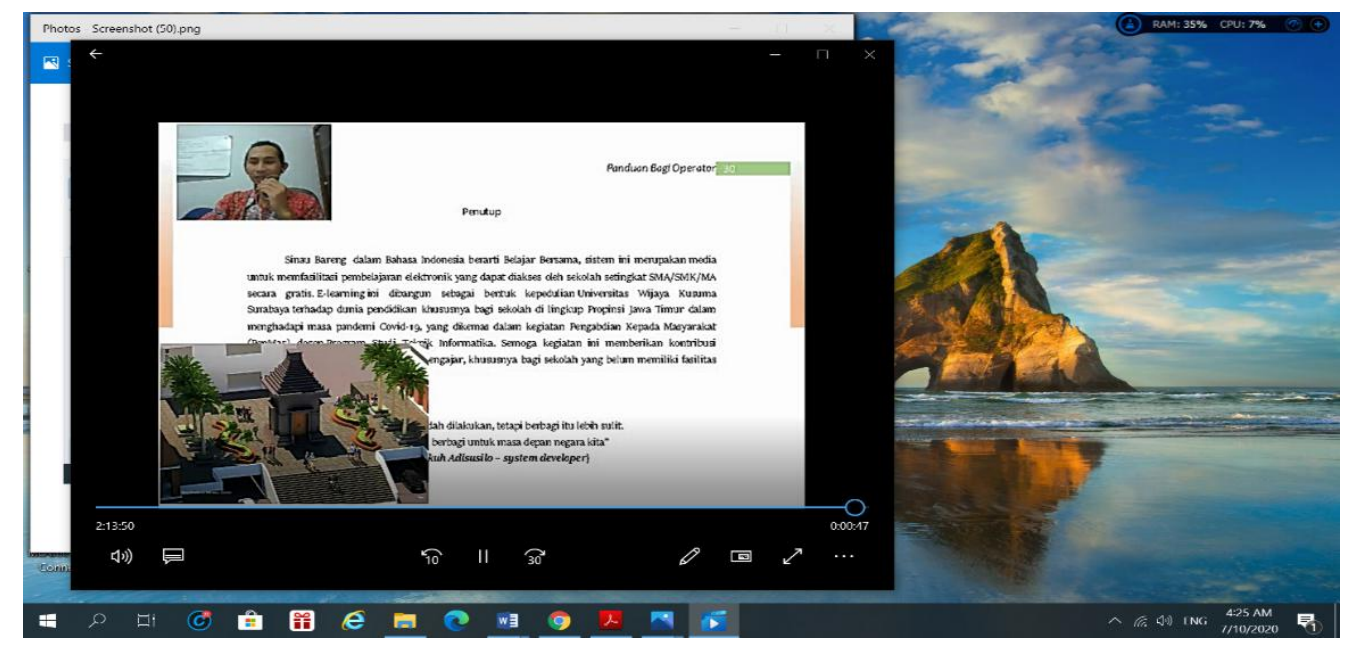

Gambar 9. Penutup Sosialisasi Guru-Guru SMKN 13 Surabaya dan Dosen-Dosen Teknik Informatika UWKS

Gambar 9 menjelaskan tampilan penutupan kegiatan pengabdian masyarakat yang telah dilaksanakan selama dua hari. Pada kesempatan ini, Dosen Teknik Informatika memberikan informasi berupa video mengenai sejarah berdirinya UWKS dan sekaligus sebagai ajang promosi untuk Program Studi Teknik Informatika.

\section{Kesimpulan}

Penyelenggaraan kegiatan pengabdian masyarakat Sosialisasi E-learning Sinau Bareng secara Virtual bagi Guru SMKN 13 Surabaya dapat dilaksanakan dengan baik melalui serangkaian kegiatan pelatihan dan pendampingan sesuai tujuan. Selain itu, kegiatan ini juga mendapatkan sambutan yang baik dari sekolah. Kegiatan seperti ini hendaknya dapat dilakukan secara berkesinambungan, mengingat pengembangan media belajar menggunakan e-learning sangat diperlukan, khususnya saat masa pandemik Corona (COVID-19) untuk memfasilitasi siswa, guru, dan orang tua/wali siswa agar lebih interaktif.

\section{Daftar Pustaka}

Arsyad, A. (2002). Media Pembelajaran, edisi 1. Raja Grafindo Persada.

Gagne, \& Briggs. (1975). Instructional Technology: Foundations. Lawrence Erlmaun Associates.

Hatip, A., Sucipto, S., \& Setiawan, W. (2019). Pelatihan Penggunaan E-learning Berbasis Media

Sosial Edmodo bagi Guru SD Negeri Mulyorejo I Surabaya. JPP IPTEK (Jurnal Pengabdian dan Penerapan IPTEK), 3(1), 61-68. https://doi.org/10.31284/j.jpp-iptek.2019.v3i1.428

Mulyasa, E. (2005). Menjadi Guru Profesional Menciptakan Pembelajaran Kreatif dan Menyenangkan. Remaja Rosdakarya.

Rusman. (2012). Model-Model Pembelajaran. Raja Grafindo Persada. 


\section{Afiliasi:}

Lestari Retnawati ${ }^{(*)}$, Nia Saurina

Universitas Wijaya Kusuma Surabaya

Jalan Dukuh Kupang XXV, Surabaya

E-mail : lestariretnawati10@gmail.com ${ }^{(*)}$,niasaurina@gmail.com

Udik Pudjianto

BPPAUD \& DIKMAS Jawa Timur

Jl. Gebang Putih No.10, Keputih, Surabaya

E-mail : udik.its@gmail.com 